\title{
Erratum to: Risk of mental disorders in family reunification migrants and native Danes: a register-based historically prospective cohort study
}

Marie Norredam • Ana Garcia-Lopez •

Niels Keiding • Allan Krasnik

Published online: 7 September 2010

(C) Swiss School of Public Health 2010

Erratum to: Int J Public Health

DOI 10.1007/s00038-010-0162-3

Unfortunately, first names and surnames of the authors were interchanged. Instead of 'Norredam Marie, GarciaLopez Ana, Keiding Niels, Krasnik Allan', they should read: 'Marie Norredam, Ana Garcia-Lopez, Niels Keiding, Allan Krasnik'.

The online version of the original article can be found under doi:10.1007/s00038-010-0162-3.

M. Norredam $(\square) \cdot$ A. Krasnik

Danish Research Centre on Migration,

Ethnicity and Health, Copenhagen, Denmark

e-mail: mano@pubhealth.ku.dk

A. Garcia-Lopez · N. Keiding

Department of Biostatistics, Institute of Public Health,

University of Copenhagen, Copenhagen, Denmark 